\title{
Scabies Surrepticius (Bullous Scabies) Presenting as Bullous Impetigo in a Child
}

\author{
Rao Muhammad Abid Khan ${ }^{1}$, Asma Muzammil ${ }^{2}$, Sualleha Siddiqi ${ }^{1}$, Shazia Muhammad Qasim ${ }^{3}$ and Ali Nadeem ${ }^{1}$ \\ ${ }^{1}$ Department of Microbiology, Sindh Institute of Urology and Transplantation (SIUT), Karachi, Pakistan \\ ${ }^{2}$ Department of Dermatology, Dr. Ruth K.M. Pfau Civil Hospital, Karachi, Pakistan \\ ${ }^{3}$ Department of Molecular Biology, Sindh Institute of Urology and Transplantation (SIUT), Karachi, Pakistan
}

\begin{abstract}
Bullous scabies (BS) is a rare and atypical presentation of scabies, usually affecting elderly males during the seventh decade of life. BS is characterised by intense pruritic eruptions, nocturnal itch, and characteristic blisters with or without burrows in scabies-prone areas. The scabies lesions might predispose patients to bacterial super-infections, resulting in bullae formation similar to bullous impetigo. The diagnosis of BS is often puzzling and delayed. Few cases of BS have been reported among children globally. We, herein, report a case of BS in an eight-year boy from Pakistan, treated successfully with $5 \%$ topical permethrin and $2 \%$ mupirocin. Complete healing was noted within four weeks with no recurrence at two months follow-up.
\end{abstract}

Key Words: Scabies, Bullous, Child, Diagnosis, Treatment.

How to cite this article: Khan RMA, Muzammil A, Siddiqi S, Qasim SM, Nadeem A. Scabies Surrepticius (Bullous Scabies) Presenting as Bullous Impetigo in a Child. J Coll Physicians Surg Pak 2022; 32(03):380-382.

\section{INTRODUCTION}

Sarcoptes scabiei var. hominis, the causative agent of scabies, affects all races and social classes of mankind and is endemic among individuals living in overcrowded, unhygienic conditions, immigrants, immunocompromised and elderly population. ${ }^{1}$ Several atypical variants of scabies such as bullous, crusted (Norwegian scabies), hidden, incognito, and nodular, have been described; and recently the term "scabies surrepticius" was introduced for these non-classic presentations. ${ }^{2}$ Bullous scabies (BS) is a rare presentation characterised by blister formation with or without nocturnal itch, burrows, pruritic papules, and nodules. BS was first reported in 1974; and to date, less than 60 cases have been reported worldwide. ${ }^{3}$ The first case of BS from Pakistan was reported in a young adult male in $2015 .{ }^{4}$ Herein, we report the first such case in a child under the age of ten years.

\section{CASE REPORT}

An 8-year boy presented with numerous skin-colored, non-erythematous, mildly itchy, fluid-filled vesicles on palms, web-spaces, flexor surfaces of the wrists, fingers, and toes. He had one-month history of intense itching with nocturnal exacerbation, primarily affecting inter-digital spaces with a gradual decrease in itching and formation of bullae.

Correspondence to: Dr. Rao Muhammad Abid Khan, Department of Microbiology, Sindh Institute of Urology and Transplantation (SIUT), Karachi, Pakistan

E-mail: raoabid101@hotmail.com

Received: January 02, 2020; Revised: February 12, 2020;

Accepted: March 02, 2020

DOI: https://doi.org/10.29271/jcpsp.2022.03.380
There was no associated fever, history of allergies, drug-abuse, or involvement of other family members. He had poorly responded to the treatment with topical anti-bacterial and anti-fungal agents. Cutaneous examination revealed two clear fluidfilled, non-tender bullae, one on the right palm measuring $20 \times 18$ $\mathrm{mm}$ (Figure $1 \mathrm{~A}$ ) and a smaller one on the left index finger measuring $22 \times 10 \mathrm{~mm}$ (Figure $1 \mathrm{~B}$ ) along with numerous small to large bullae on other areas (Figures $2 \mathrm{~A}$ and $\mathrm{B}$ ).

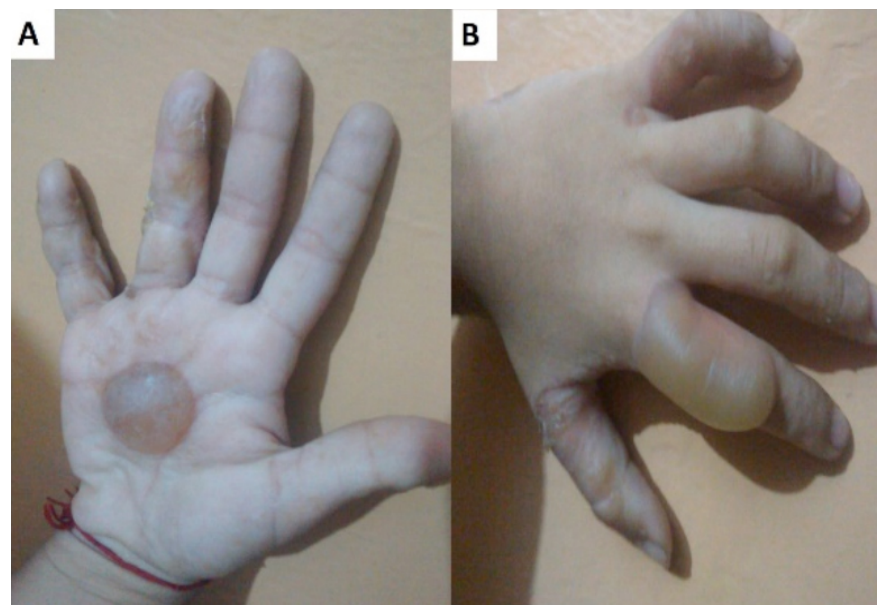

Figure 1: Largetense bullae (A) On right palm (B) On leftindex finger.

The differential diagnosis included pompholyx, bullous impetigo, chronic bullous dermatosis of childhood, and BS.

The skin scrapings from margins of the lesions on inter-digital spaces of hands were obtained. The fluid from bulla on the right palm was also collected for culture and wet mount preparation. Wet mount preparation was unrevealing; whereas, culture was positive for staphylococcus aureus. The direct microscopy of skin 
scrapings in $10 \%$ potassium hydroxide revealed multiple mites of sarcoptes scabiei var. hominis confirming the diagnosis of BS (Figures $3 \mathrm{~A}$ and $\mathrm{B}$ ).

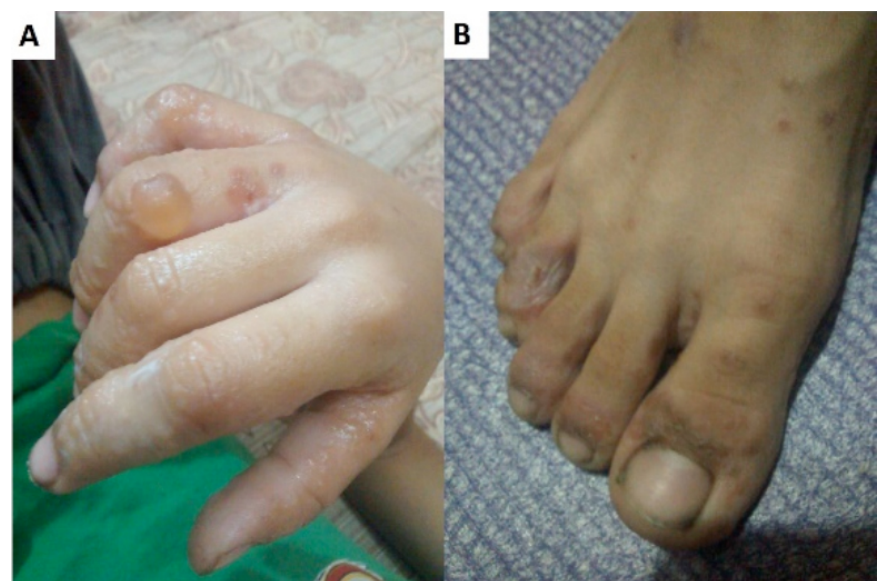

Figure 2: (A) Multiple bullae and pruritic lesions on fingers and web spaces of right hand. (B) Numerous pruritic lesions on inter-digital regions and fingers of right foot.

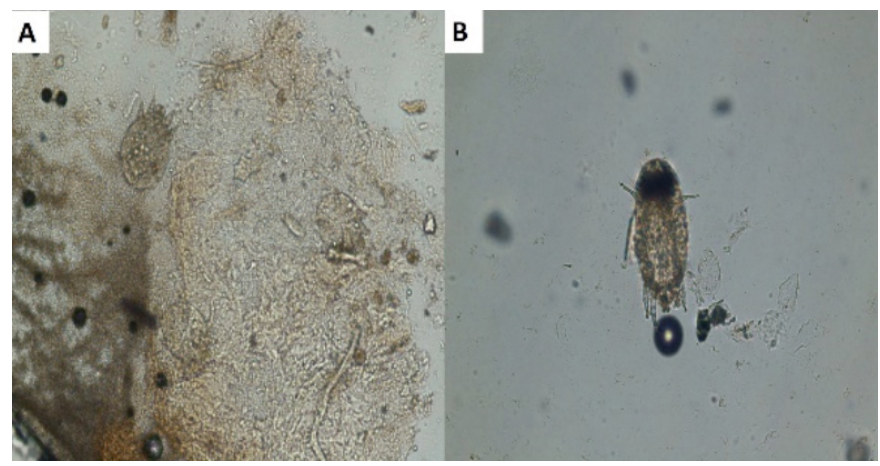

Figure 3: Light microscopic view of skin scrapings from margins of interdigital lesions on right hand in $10 \% \mathrm{KOH}$ mount preparation. (A) Three sarcoptes scabiei var. hominis adult mites and scybala (original magnification, $\times 100$ ). (B) Afemalesarcoptesscabieivar. hominis adultmite (original magnification, $\times 400$ ).

The patient and his close family members were prescribed $5 \%$ permethrin topical lotion on the whole body below the neck and submerging of linens within boiling water. The bacterial super-infection was treated with mupirocin $2 \%$ ointment.

The 'wound toilet' for ruptured bullae was done with $10 \%$ povidone-iodine and normal saline for three weeks. Complete healing was noted within four weeks with no recurrence over the following two months.

\section{DISCUSSION}

Scabies is a neglected, persistently endemic and highly contagious skin infestation worldwide. The transmission occurs through prolonged skin contact and fomites. Annually over 300 million individuals are affected with scabies. ${ }^{1}$ The precise estimates are difficult as most of the reports are based on hospital outpatient records, but the estimated prevalence, in a systematic review report from most parts of the world, is $0.2-71.4 \% .^{5}$ Scabies has been estimated to be more prevalent in Pakistan, i.e. $38.15 \%$, compared to neighbouring countries, such as India, where its prevalence is $21.54 \%$ and Iran, $4.1 \%$. $^{6-8}$
BS is a rare and atypical variant with predilection in elderly males. ${ }^{4}$ The age of onset ranges from 1-89 years; most commonly affecting people are in the seventh decade of life. ${ }^{3}$ The high prevalence among males has been attributed to frequent close contact with other persons, different lifestyles, and greater exposure to potential mite sources. Low immunity and tendency to bed-rest might justify the higher prevalence among aged people. Literature review reveals few cases of BS in children younger than ten years globally; ${ }^{3,9,10}$ and to our knowledge, this is the first such report of BS in a boy from Pakistan. Recently, it was hypothesised that scarcity of BS reports among children might be largely due to misdiagnosis, considering scabies as a neglected disease. ${ }^{9}$

BS is characterised by intense pruritic eruptions, nocturnal itch, tense or flaccid bullae, nodules and burrows in scabies-prone areas, most commonly on hands, fingers, web-spaces, and feet. BS lesions morphologically mimic the autoimmune disorder, bullous pemphigoid (BP), which mainly affects elderly individuals. ${ }^{3} \mathrm{BS}$ may have remarkable morbidity related to the development of various secondary lesions including papules, impetigo, folliculitis, dermatitis and particularly bullae. The mostcommon proposed mechanism for bullae formation is the super-infection of scabies lesions with staphylococcus aureus. ${ }^{4}$

Skin scraping test (SST) for scabies mites, eggs, and/or the scybala remains the frequently used test for diagnosis of scabies and scabies surrepticius. Moreover, the diagnosis of scabies surrepticius and scabies among children, immunocompromised, and elderly can be more challenging. Alternatively, skin biopsy, burrow ink test and dermoscopy are highly sensitive techniques. ${ }^{1}$

Despite the severity and atypical presentation, treatment remains the same for BS and non-bullous scabies. The treatment of choice is either topical $5 \%$ permethrin and/or oral ivermectin with success rate of more than $90 \% .{ }^{4}$ Other alternative treatment choices are topical sulphur (6-10\%), 10\% crotamiton, and $0.5 \%$ malathion. ${ }^{1}$ We highly emphasise the importance of considering scabies among children presenting with unexplained onset of nocturnal pruritic bullous lesions.

\section{PATIENT'S CONSENT:}

Informed consent was obtained from the child's father to publish the data concerning this case.

\section{CONFLICT OF INTEREST:}

The authors declared no conflict of interest

\section{AUTHORS' CONTRIBUTION:}

RMAK: Study conception and design, data acquisition and analysis, Interpretation, critical revision, drafting, final approval.

AM: Analysis, Interpretation, drafting, critical revision, final approval.

SS: Analysis, interpretation, critical revision, final approval.

SMQ: Design and conception, analysis, drafting, final approval. AN: Analysis and interpretation, critical revision, final approval. 


\section{REFERENCES}

1. Leung AKC, Lam JM, Leong KF. Scabies: A neglected global disease. Curr Pediatr Rev 2020; 16(1):33-42. doi: 10.2174/ 1573396315666190717114131.

2. Cohen PR. Scabies masquerading as bullous pemphigoid: Scabies surrepticius. Clin Cosmet Investig Dermatol 2017; 10:317-24. doi: 10.2147/CCID.S145494.

3. Li LY, Sun H, Li XY, Liu JH, Liu Wx, Luo DQ. Hemorrhagic bulla: A rare presentation of scabies. Ann Transl Med 2019; 7(5):107. doi: 10.21037/atm.2019.02.09.

4. Maan MA, Maan MS, Sohail AM, Arif M. Bullous scabies: A case report and review of the literature. Bmc Res Notes 2015; 8:254. doi: 10.1186/s13104-015-1146-4.

5. Romani L, Steer AC, Whitfeld MJ, Kaldor JM. Prevalence of scabies and impetigo worldwide: A systematic review. Lancet Infect Dis 2015; 15(8):960-7. doi: 10.1016/S1473-
3099(15)00132-2

6. Chaudhry F, Hameed K, Naz S, Min D, Paolotizzani RA. Scabies prevalence and risk factors in Pakistan: A hospitalbased survey. Biomed J Sci Tech Res 2018; 2(2).

7. Sardana K, Mahajan S, Sarkar R, Mendiratta V, Bhushan P, Koranne RV, et al. The spectrum of skin disease among indian children. Pediatr Dermatolo 2009; 26(1):6-13.

8. Baghestani S, Zare S, Mahboobi AA. Skin disease patterns in hormozgan, iran. Int J Dermatol 2005; 44(8):641-5. doi: 10.1111/j.1365-4632.2004.02140.x.

9. Luo ZY, Zeng M, Gao Q, Zhao YK, Sarkar R, Liao SP, et al. Case report: Bullous scabies in two children below 10 years. Am J Trop Med Hyg 2017; 97(6):1746-8. doi: 10.4269/ajtmh.17-0344.

10. Guergue diaz de cerio O, Gonzalez Hermosa MD, Ballestero Diez M. Bullous scabies in a 5-year-old child. J pediatr 2016; 179:270-e1. doi: 10.1016/j.jpeds.2016.08.078. 